\title{
El diálogo entre el Tribunal Constitucional de Chile y la Doctrina
}

\author{
Marisol Peña Torres ${ }^{1}$
}

\section{RESUMEN}

La evolución de la jurisprudencia del Tribunal Constitucional chileno muestra, a través de sus distintas etapas, un recurso cada vez más permanente a la doctrina, nacional y extranjera, como a la jurisprudencia comparada, lo cual se estima fundamental frente a su tarea de delimitar el sentido y alcance de conceptos jurídicos indeterminados como los que se contienen en la Carta Fundamental.

\section{Palabras Clave}

Tribunal Constitucional, Jurisprudencia Constitucional, Doctrina, Derecho Comparado.

\section{Abstract}

The evolution of the jurisprudence of the Chilean Constitutional Tribunal shows, trough its different steps, a strong tendency to use national and foreign doctrine and comparative judicial decisions as well. Those methods are considered fundamental in order to clarify the real sense of undefined legal concepts inside the Constitutions.

\section{Key Words}

Constitutional Tribunal, Constitutional Decisions, Doctrine, Comparative Law

Profesora Titular de Derecho Constitucional y de Derecho Internacional Público de la Pontificia Universidad Católica de Chile. Ministra del Tribunal Constitucional de Chile. 


\section{INTRODUCCIÓN}

El tema del diálogo entre los Tribunales Constitucionales y la doctrina tiene un trasfondo que, en mi concepto, no puede dejar de plantearse desde el inicio. Se trata de establecer si la argumentación del juez constitucional debe ser autosuficiente, prescindiendo de argumentos provenientes de la doctrina, del derecho comparado o de la jurisprudencia emanada de otros tribunales o si, por el contrario, es necesario, o, al menos, conveniente, que el juez constitucional enriquezca sus puntos de vista con aquellas reflexiones, aportes o críticas que provienen de quienes forman parte de la "doctrina especializada"; lo anterior, sin perjuicio de acudir a elementos normativos y jurisprudenciales ajenos al sistema jurídico de que se trata.

Sobre el particular, me propongo reseñar la experiencia del Tribunal Constitucional chileno en esta materia, para lo cual, necesariamente, deberé partir por referirme a las diversas etapas de su desenvolvimiento.

\section{La consideración de la doctrina por parte del Tribunal Constitucional de Chile}

Suelen distinguirse tres etapas en el desarrollo del Tribunal Constitucional chileno. La primera se inicia con su instalación, en septiembre del año 1971, después de haber sido creado por la reforma constitucional del año 1970. Esta primera etapa concluye en noviembre de 1973, cuando el Tribunal es disuelto por el Decreto Ley № 119, de 5 de noviembre de 1973, publicado en el Diario Oficial de 10 de noviembre del mismo año.

La segunda etapa se inicia en el año 1981, después de haber sido reinstaurado el Tribunal Constitucional por la Constitución que entró a regir el 11 de marzo de ese mismo año. Este período se extiende hasta la aprobación de la reforma constitucional del año 2005, que cambió sustantivamente la 
composición y atribuciones del Tribunal Constitucional y que entró a regir seis meses después de su publicación en el Diario Oficial (Véase la disposición transitoria 16a․ de la Constitución).

La tercera etapa se inicia con la vigencia de la reforma constitucional del 2005, a fines de febrero del año 2006, y se extiende hasta el presente. De esta nueva etapa cabe destacar el conocimiento y resolución, por parte del Tribunal Constitucional, de las acciones de inaplicabilidad por inconstitucionalidad de la ley (C. P. art 93, inciso primero, numeral 6) -que representan actualmente el $85 \%$ de la labor que desempeña nuestra Magistratura (Tribunal Constitucional, Santiago, marzo de 2011) - y el pronunciamiento sobre la inconstitucionalidad de preceptos legales declarados previamente inaplicables (C. P. art 93, inciso primero, numeral 7), que puede tener su origen en una acción pública o en un proceso iniciado de oficio por el propio Tribunal.

Trataremos de establecer, a continuación, cuál ha sido la posición del Tribunal Constitucional, en cada una de estas etapas, respecto de la utilización de doctrina, nacional y extranjera, como fundamento de sus decisiones.

\subsection{Jurisprudencia constitucional 1971-1973}

En lo que se refiere a la primera etapa mencionada, el examen de los 17 fallos dictados por este originario Tribunal Constitucional permite constatar que si bien la cita de fallos de tribunales extranjeros no formó parte de las decisiones de los jueces de entonces, el recurso a opiniones emanadas de la doctrina especializada, sí estuvo presente.

Lo anterior se observa ya en la sentencia recaída en el Rol № 1, de 1ํ de noviembre de 1971, referida a la solicitud de inconstitucionalidad de diversas 
normas del Proyecto de Ley de Presupuestos para el año 1972, en la que, junto con citarse legislación presupuestaria francesa y belga, se alude a doctrina extranjera (la obra "El Parlamento Británico" traducida por José Rodríguez Olazábal y el "Traité de Science Administrative", de varios autores, dirigidos por el Decano George Vedel en la sentencia Rol No. 1, considerandos 13 y 14).

En la sentencia referida al Rol № 2, de 25 de marzo de 1972, que resuelve la solicitud de inconstitucionalidad planteada por el Presidente de la República respecto de un proyecto de ley en el que no se habían cumplido, a su juicio, las formalidades para vencer el veto presidencial, se cita doctrina nacional para avalar la competencia que la Constitución le asigna al Tribunal Constitucional para resolver este tipo de conflictos previstos, en ese momento, en el artículo 78 b), letra a), de la Constitución Política de 1925. Específicamente se cita la obra del profesor Carlos Andrade, "Elementos de Derecho Constitucional Chileno", para recordar el contenido del informe emitido por la Comisión de Constitución, Legislación y Justicia de la Cámara de Diputados durante el primer trámite parlamentario del Proyecto de Reforma Constitucional que incorporó la atribución del Tribunal Constitucional de pronunciarse sobre los proyectos de ley sometidos a la aprobación del Congreso, donde quedó en evidencia que las cuestiones de constitucionalidad a que aludía el precepto respectivo eran tanto las relativas al contenido sustantivo de los proyectos de ley como aquellas atinentes al procedimiento constitucional de formación o generación de la ley (considerando 8).

Alude también dicha sentencia a la opinión del profesor chileno Alejandro Silva Bascuñán, en la obra "Reforma Constitucional 1970", en la que menciona como un ejemplo de cuestión de constitucionalidad que puede suscitarse en la tramitación de un proyecto de ley, "la forma en que deben calificarse y votarse las observaciones formuladas por el Presidente de la República, según su respectiva índole aditiva; supresiva o substitutiva". 
A su turno, en el fallo recaído en el Rol $N^{\circ} 14$, de 9 de abril de 1973, que decidió el requerimiento de inconstitucionalidad formulado por el Presidente de la República respecto del proyecto de ley sobre anticipo de reajuste a los trabajadores, se citan párrafos de un artículo del ex Presidente de la República, Eduardo Frei Montalva, denominado "La reforma constitucional en su contexto histórico-político", que justifican las razones que tuvo el Constituyente chileno para reforzar la iniciativa exclusiva de ley del Poder Ejecutivo en materias económico-sociales, lo que aparece también avalado por las reflexiones del jurista chileno Francisco Bulnes Ripamonti, en su obra "Relaciones y conflictos entre los órganos del poder Estatal." (Considerandos $12^{\circ}$ y 13$)$.

Como puede observarse, en estas primeras decisiones, la invocación por el Tribunal Constitucional de opiniones provenientes de la doctrina fue más bien escasa y, en general, se circunscribió a citas de autores nacionales que daban cuenta del alcance de alguna institución específica contenida en la Constitución Política y que estaba siendo analizada por nuestra Magistratura.

\subsection{Jurisprudencia constitucional 1981-2005}

La segunda etapa del Tribunal Constitucional chileno, iniciada en el año 1981, no marca, en un comienzo, mayores diferencias con la tendencia observada durante la primera etapa aludida. Cabe tener presente, en este sentido, que las atribuciones ejercidas tanto por el primero como por el segundo Tribunal son similares: controles preventivos obligatorios de constitucionalidad de preceptos legales y pronunciamientos referidos a requerimientos de constitucionalidad deducidos por órganos legitimados o mediante acción pública, en su caso.

Es así como en los fallos de los primeros años, a partir del reestablecimiento del Tribunal, la cita de sentencias extranjeras es casi nula observándose solamente una referencia a alguna doctrina extranjera seleccionada como 
ocurre en la sentencia Rol № 12, de 16 de julio de 1982, y en la sentencia Rol № 15, de 29 de noviembre de 1982.

En la primera de ellas se ejerció el control de constitucionalidad del proyecto de ley que interpretaba la garantía constitucional del derecho de propiedad en relación con la reajustabilidad de las pensiones. Argumentando sobre la diferencia entre derechos adquiridos y meras expectativas, el Tribunal recurrió a una cita del profesor francés Gastón Jéze, en su obra, "Derecho Administrativo" (1948, considerando 14), así como a M. Merlin, en su "Repertoire Universel et Raisonné et Jurisprudence " y al tratadista italiana Gabba, en su texto sobre "Teoría de la retroactividad de la ley" (1891-1898, considerando 16).

La sentencia recaída en el Rol № 15, por su lado, tenía por objeto pronunciarse sobre el requerimiento formulado por la Junta de Gobierno respecto del proyecto de ley que modificaba el artículo 6을 del Decreto Ley № 2.200, de 1978, y sobre diversos artículos del Decreto Ley № 2.758, de 1979. Nuevamente, el Tribunal procede a citar a los autores extranjeros Merlin y Gabba para referirse al concepto de derechos adquiridos (considerando 3).

La primera oportunidad en que este Tribunal de la segunda etapa acude a sentencias de tribunales extranjeros se produce, en el año 1985, con ocasión del requerimiento formulado por un grupo de personas, en ejercicio de una acción pública, con el objeto de que se declarara la inconstitucionalidad de las organizaciones Movimiento Democrático Popular (MDP), Partido Comunista de Chile, Movimiento de Izquierda Revolucionaria (MIR) y Partido Socialista de Chile (fracción encabezada por Clodomiro Almeyda), todo ello en virtud de lo dispuesto en el artículo 8ำ primitivo de la Carta Fundamental (Sentencia Rol № 21, de 31 de enero de 1985) en su redacción original:

"Todo acto de persona o grupo destinado a propagar doctrinas que atenten contra la familia, propugnen la violencia o una concepción de la sociedad, del Estado o del orden jurídico, de carácter totalitario o fundada en la lucha de 
clases, es ilícito y contrario al ordenamiento institucional de la República. Las organizaciones y los movimientos o partidos políticos que por sus fines o por la actividad de sus adherentes tiendan a esos objetivos, son inconstitucionales. Corresponderá al Tribunal Constitucional conocer de las infracciones a lo dispuesto en los incisos anteriores. Sin perjuicio de las demás sanciones establecidas en la Constitución o en la ley, las personas que incurran o hayan incurrido en las contravenciones señaladas precedentemente no podrán optar a funciones o cargos públicos, sean o no de elección popular, por el término de diez años contado desde la fecha de resolución del Tribunal. Tampoco podrán ser rectores o directores de establecimientos de educación ni ejercer en ello funciones de enseñanza, ni explotar un medio de comunicación social o ser directores o administradores del mismo, ni desempeñar en él funciones relacionadas con la emisión o difusión de opiniones o informaciones; ni podrán ser dirigentes de organizaciones políticas o relacionadas con la educación o de carácter vecinal, profesional, empresarial, sindical, estudiantil o gremial en general, durante dicho plazo. Si las personas referidas anteriormente estuvieren a la fecha de la declaración del Tribunal, en posesión de un empleo o cargo público, sea o no de elección popular, lo perderán, además, de pleno derecho. Las personas sancionadas en virtud de este precepto no podrán ser objeto de rehabilitación durante el plazo señalado en el inciso cuarto. La duración de las inhabilidades contempladas en este artículo se elevará al doble en caso de reincidencia."

En el considerando $2^{\circ}$ - de dicha sentencia se alude a jurisprudencia del Tribunal Constitucional alemán, en los siguientes términos:

“(...) el Tribunal Constitucional de Alemania Federal, al aplicar el artículo 21 inciso $2^{\circ}$ de su Constitución, que es la fuente inmediata del artículo $8^{\circ}$ inciso $2^{\circ}$ de nuestra Carta Fundamental, ha expresado: "El programa o "los fines del partido" en el sentido de esta frase no se averiguarán 
solamente en programas, declaraciones, principios oficiales, etc., sino se investigarán también en la imagen completa del partido, de lo que desea lograr, tal como se manifiesta en sus programas secretos y fines, en discursos, escritos, material de propaganda, en el comportamiento y la posición personal de los órganos y de los adherentes. En suma, del estilo político que adopta el partido. (Grundgesetz-Kommentar, Maunz, Theodor/Düring, Gunter. Art. 21, n. 5, cc., 1983)."

Como puede apreciarse, la cita no está extraída directamente del fallo respectivo sino que de la referencia respectiva que realiza un autor. A partir de ese momento resulta difícil encontrar algún fallo que aluda a sentencias de otros tribunales similares o a doctrina especializada. Probablemente, uno de los fallos que marca un punto de inflexión en tal sentido está constituido por la sentencia recaída en el Rol $\mathrm{N}^{\circ} 346$, de 8 de abril de 2002, que, como muchos otros tribunales del mundo, debió pronunciarse sobre la constitucionalidad del Estatuto de Roma, que crea la Corte Penal Internacional. En ella nuestro Tribunal Constitucional extendió su pronunciamiento al rango jerárquico de los tratados internacionales dentro de nuestro ordenamiento jurídico siguiendo, al efecto, la opinión vertida por el profesor Alejandro Silva Bascuñán, en la Comisión de Estudio de la Nueva Constitución, según la cual los tratados internacionales de derechos humanos están situados bajo la Constitución, pero por sobre las normas de rango legal (considerando $\mathrm{N}^{\circ} 75^{\circ}$ ). Esta precisión tiene mucha importancia, pues la redacción del artículo $5^{\circ}$, inciso segundo, de la Constitución Política -después de la reforma de 1989- ha dado lugar a posiciones muy diversas en la doctrina nacional y también en la jurisprudencia de los tribunales ordinarios de justicia. De esta forma, en el citado Rol №346, el Tribunal Constitucional chileno fijó su posición sobre la materia, la cual no ha sido modificada por ninguna sentencia posterior hasta la fecha. La reforma constitucional de agosto de 1989 incorporó una frase final al inciso segundo del artículo $5^{\circ}$ de la Constitución Política señalando 
que: "Es deber de los órganos del Estado respetar y promover los derechos garantizados por esta Constitución, así como por los tratados internacionales ratificados por Chile y que se encuentren vigentes."

\subsection{Jurisprudencia constitucional $2006-2011$}

En lo que se refiere, ahora, a la jurisprudencia emanada del Tribunal Constitucional de la tercera etapa, esto es, de aquella que se inicia con la vigencia de la reforma constitucional del año 2005, es posible apreciar un incremento sostenido de las citas y referencias tanto a sentencias emanadas de tribunales extranjeros como de tribunales internacionales (Corte Interamericana de Derechos Humanos), pero también del recurso a la doctrina especializada, tanto nacional como extranjera. Como ha sostenido el ex Presidente de nuestra Magistratura, profesor José Luis Cea Egaña, en esta etapa, "merece mención la invocación de doctrina nacional y extranjera reciente, rebasando el uso de fuentes arcaicas y repetidas, como en las primeras dos épocas del tribunal." (CEA EGAÑA, J. L, Santiago, 2009). Esta invocación creciente de fuentes como la jurisprudencia extranjera y la doctrina se produce, especialmente, en las sentencias recaídas en el ejercicio de acciones de inaplicabilidad por inconstitucionalidad de preceptos legales, en virtud de la nueva competencia que la aludida reforma constitucional confiara al Tribunal Constitucional en el artículo 93, inciso primero, $N^{\circ} 6^{\circ}$ de la Carta Fundamental. El artículo $93 \mathrm{~N}^{\circ} 6^{\circ}$ de la Carta Fundamental prescribe: "Son atribuciones del Tribunal Constitucional: 6ํㅜ Resolver, por la mayoría de sus miembros en ejercicio, la inaplicabilidad de un precepto legal cuya aplicación en cualquier gestión que se siga ante un tribunal ordinario o especial, resulte contraria a la Constitución." Una descripción de los principales aspectos de la reforma constitucional de 2005 en lo referente al Tribunal Constitucional puede consultarse en PEÑA TORRES, Marisol. Los desafíos para la justicia constitucional chilena a partir de la reforma de 2005. Suprema Corte de 
Justicia de la Nación de México. Colección Tribunales Constitucionales de Iberoamérica, № 1, diciembre de 2006.

Esta técnica hermenéutica ha sido ya estudiada por parte de la doctrina nacional, por ejemplo, en el artículo del profesor Manuel Núñez Poblete, "La influencia del Derecho y la Literatura Jurídica en la Formación de la Jurisprudencia del Tribunal Constitucional chileno."

¿Cómo se ha producido esta interacción entre la Magistratura Constitucional chilena y la doctrina especializada en relación con el ejercicio de la acción de inaplicabilidad por inconstitucionalidad de preceptos legales como manifestación del control concreto de constitucionalidad? La respuesta parece discurrir por dos vertientes diferentes.

La primera dice relación con la referencia que el propio Tribunal Constitucional realiza, en sus sentencias, a la doctrina especializada, fundamentalmente para contribuir a precisar el sentido y alcance de aquellos conceptos incluidos en la Constitución que revisten el carácter de conceptos jurídicos indeterminados o cuyo enunciado normativo se muestra particularmente abierto.

Este es el caso del tradicional principio de igualdad ante la ley que nuestra Constitución recoge en su artículo $19 \mathrm{~N}^{\circ} 2^{\circ}$, en particular, en su inciso segundo, que señala: "Ni la ley ni autoridad alguna podrán establecer diferencias arbitrarias."

La jurisprudencia tradicional de nuestro Tribunal siguió, en esta materia, al profesor argentino Segundo Linares Quintana, quien explicaba que la razonabilidad es el "cartabón o standard" de acuerdo con el cual debe apreciarse la medida de igualdad o desigualdad (Sentencias Roles Nº. 28, 53 y 219). 
Sin embargo, con ocasión de un requerimiento deducido contra los artículos 4 y 29 de las Leyes $N^{\circ}$ s 18.549 y 18.669, referentes a la reajustabilidad de determinadas pensiones (Sentencia Rol № 790, diciembre, 2007), el Tribunal Constitucional decidió examinar su jurisprudencia previa concluyendo que:

"El examen de la jurisprudencia de diversos Tribunales Constitucionales, como el español y el alemán, da cuenta de que no basta (...) que la justificación de las diferencias sea razonable sino que además debe ser objetiva. La Suprema Corte de Justicia de México concuerda con este criterio cuando señala que: "Si bien el emisor de la norma puede prever situaciones fácticas que requieren un trato diferente, éste debe sustentarse en criterios razonables y objetivos que lo justifiquen, sin dejarlo al capricho o voluntad del legislador". (Sentencia 1629/2004 en Semanario Judicial de la Federación y su Gaceta, Tomo XXII, noviembre de 2005, p. 40)."

Asimismo es necesario atender a la finalidad perseguida por el legislador para intervenir el derecho fundamental de que se trata, la que debe ser adecuada, necesaria y tolerable para el destinatario de la misma. (Tomás Ramón Fernández. De la arbitrariedad del legislador. Una crítica de la jurisprudencia constitucional. Editorial Civitas, Madrid, 1988, pp. 34 y 42).

El Tribunal Constitucional de España ha señalado, específicamente, que "para que la diferenciación resulte constitucionalmente lícita no basta que lo sea el fin que con ella se persigue, sino que es indispensable además que las consecuencias jurídicas que resultan de tal distorsión sean adecuadas y proporcionadas a dicho fin, de manera que la relación entre la medida adoptada, el resultado que produce y el fin pretendido por el legislador supere un juicio de 
proporcionalidad en sede constitucional, evitando resultados especialmente gravosos o desmedidos". (Sentencias 76/1990 y 253/2004).

Por su parte, la Suprema Corte de Justicia de México precisa que, para los efectos de considerar si, en un caso concreto, una discriminación está constitucionalmente vedada, debe determinar, "en primer lugar, si la distinción legislativa obedece a una finalidad objetiva y constitucionalmente válida: el legislador no puede introducir tratos desiguales de manera arbitraria, sino que debe hacerlo con el fin de avanzar en la consecución de objetivos admisibles dentro de los límites marcados por las previsiones constitucionales, o expresamente incluidos en ellas. En segundo lugar, es necesario examinar la racionalidad o adecuación de la distinción hecha por el legislador: es necesario que la introducción de una distinción constituya un medio apto para conducir al fin u objetivo que el legislador quiere alcanzar, es decir, que exista una relación de instrumentalidad entre la medida clasificatoria $y$ el fin pretendido. En tercer lugar, debe cumplirse con el requisito de la proporcionalidad: el legislador no puede tratar de alcanzar objetivos constitucionalmente legítimos de un modo abiertamente desproporcional, de manera que el juzgador debe determinar si la distinción legislativa se encuentra dentro del abanico de tratamientos que pueden considerarse proporcionales, habida cuenta de la situación de hecho, la finalidad de la ley y los bienes y derechos constitucionales afectados por ella (....). Por último, es de importancia determinar en cada caso respecto de qué se está predicando con la igualdad ...". (Sentencia 988/2004, en Semanario 
Judicial de la Federación y su Gaceta, Tomo XX, diciembre de 2004, p. 362)." (Considerando $22^{\circ}$ ).

Estos mismos argumentos jurisprudenciales fueron recogidos, más adelante, en la sentencia que decidió el requerimiento de inaplicabilidad deducido contra el artículo 595 del Código Orgánico de Tribunales -abogado de turno(Sentencia Rol № 755, marzo, 2008) que constituyó el antecedente inmediato de la derogación de la expresión "gratuitamente" contenida en esa norma (Sentencia Rol No 1.254, julio, 2009).

La evolución jurisprudencial que ha experimentado el principio de la igualdad ante la ley en el Tribunal Constitucional chileno se completa con las referencias extraídas de fallos del Tribunal Constitucional alemán que distingue entre igualdades esenciales e igualdades no esenciales. Estas referencias se incluyen, por primera vez, en una de las sentencias de inaplicabilidad referidas el artículo 38 ter de la Ley de Isapres - Instituciones de Salud Previsional- (Sentencia Rol № 1273, abril, 2010) para venir a consolidarse en la sentencia recaída en el Rol № 1710, que declaró la inconstitucionalidad de cuatro numerales del inciso tercero del aludido artículo 38 ter, con fecha 6 de agosto de 2010. En esa decisión se recuerda que, siguiendo la jurisprudencia del Tribunal Constitucional alemán, "estamos en presencia de una igualdad esencial cuando "personas, grupos de personas o situaciones sobre la base de un punto de partida (tertium comparationis), son comparables", de lo que, consecuentemente, el Tribunal Constitucional Federal alemán ha decidido que la Ley Fundamental considera arbitrario y, por ende, inconstitucional, tratar desigualmente a las igualdades esenciales, así como tratar igualmente a las desigualdades esenciales. Además se agrega la denominada "nueva fórmula", consistente en considerar lesionada la igualdad ante la ley cuando un grupo de destinatarios de la norma, comparado con otro grupo de destinatarios de la norma, son tratados de 
manera distinta, a pesar de que entre ambos grupos no media ninguna diferencia de tal entidad o importancia que pudiera justificar un tratamiento desigual. Para poder dimensionar tales situaciones, esta fórmula requiere expresamente una ponderación en el sentido de examen de proporcionalidad especialmente respecto de una diferencia de trato de gran intensidad, para lo cual se requiere que aquélla persiga un fin legítimo, que esa búsqueda sea necesaria y que presente una razonable relación con el valor del fin propuesto." (Considerando 100).

Así, la actual concepción que sustenta el Tribunal Constitucional de Chile respecto de la igualdad ante la ley se muestra tributaria tanto del aporte de la doctrina como de la jurisprudencia extranjera.

Otro ejemplo en virtud del cual la doctrina ha aportado a la labor del Tribunal de dotar de contenido a conceptos constitucionales, de por sí amplios o ambiguos, dice relación con el concepto de "apremio ilegítimo" utilizado en el artículo 19 № 1, inciso final, de la Carta Fundamental, que expresa: "Se prohíbe la aplicación de todo apremio ilegítimo." En este sentido, el fallo recaído en el rol № 519, de 5 de junio de 2007, recuerda que:

"(...) tal como lo ha señalado la doctrina, "la Constitución prohíbe la fuerza ilegítima, ya que hay situaciones en que ella está autorizada por la ley dentro de ciertos límites y con variados requisitos" (Enrique Evans de la Cuadra, Los Derechos Constitucionales, Tomo I, Editorial Jurídica de Chile, año 2004, p. 115). En efecto, como lo consigna otro autor, "existen ciertos apremios que se estiman legítimos: un embargo, el arresto, la incomunicación, entre otros." (Mario Verdugo M. y otros, Derecho Constitucional, Tomo I, Editorial Jurídica de Chile, año 1999, p. 202) precisando que "el arresto como medida de apremio se ordena a fin de que el afectado cumpla una prestación o realice una determinada gestión ante 
los tribunales de justicia -pague una pensión alimenticia 0 preste declaración ante un tribunal-“ (Ibid.) (...)”. (Considerando $36^{\circ}$ ).

Un tercer ejemplo ilustrativo sobre la forma en que el Tribunal Constitucional de Chile recurre a la doctrina para precisar el alcance de ciertos conceptos constitucionales se encuentra en la sentencia dictada en el Rol № 559, de 7 de junio de 2007, en relación con el concepto de "leyes penales en blanco", pues el artículo 19 № 3, inciso final, de la Constitución Política indica que: "Ninguna ley podrá establecer penas sin que la conducta que se sanciona esté expresamente descrita en ella."

En la referida sentencia, nuestra Magistratura expresó que: "Según una de sus numerosas definiciones, las leyes penales en blanco son aquellas leyes que solamente contienen una conminación penal y que respecto del contenido prohibitivo remiten a leyes, reglamentos e incluso actos administrativos, que se han promulgado autónomamente en otro tiempo o lugar. De acuerdo con ello hay que distinguir entre norma sancionatoria y norma complementaria. El tipo de la ley en blanco sólo se forma con la norma complementaria" (HansHeinrich, 1978).

La segunda fuente de interacción entre el Tribunal Constitucional de Chile y la doctrina se refiere a la crítica que diversos autores chilenos han realizado a la labor cumplida por nuestra Magistratura respeto del ejercicio de su competencia de decidir las acciones de inaplicabilidad de preceptos legales como también respecto de diversas cuestiones de inconstitucionalidad abstracta. El artículo $93 \mathrm{~N}^{\circ} 7^{\circ}$ de la Constitución Política indica: "Son atribuciones del tribunal Constitucional: $7^{\circ}$ Resolver, por la mayoría de los cuatro quintos de sus integrantes en ejercicio, la inconstitucionalidad de un 
precepto legal declarado inaplicable en conformidad a lo dispuesto en el numeral anterior."

Desde luego, los fallos del Tribunal Constitucional son frecuentemente reseñados y comentados en publicaciones periódicas como "La Gaceta Jurídica" o el periódico electrónico "Diario Constitucional". Asimismo, las Revistas de Derecho de las principales universidades del país suelen contener artículos que se refieren al alcance de determinadas sentencias pronunciadas por el Tribunal Constitucional como también incluyen síntesis comentadas de las mismas en sus secciones de jurisprudencia. Asimismo, algunos centros de estudio especializados, como el Instituto Libertad y Desarrollo, mantienen una publicación anual "Sentencias destacadas" que comenta algunos de los fallos más relevantes dictados por nuestro Tribunal en el período precedente.

Por otra parte, casi todas las Facultades de Derecho del país han realizado seminarios para analizar el alcance de determinados fallos como es el caso de los que han recaído en la inconstitucionalidad del decreto supremo que autorizaba la distribución gratuita de la "Píldora del Día Después" (sentencia Rol No. 740) en los consultorios dependientes del Servicio Nacional de Salud; o el que declaró la inconstitucionalidad de parte de un artículo de la ley que regula a las Instituciones de Salud Previsional (ISAPRES) en su facultad de fijar los precios de los planes de salud (sentencia Rol No. 1710); o el que se pronunció sobre el proyecto modificatorio de la ley orgánica constitucional del propio Tribunal Constitucional en cuanto a permitir el control posterior de constitucionalidad de tratados internacionales (sentencia Rol No. 1288) o, más recientemente, el que decidió la inaplicabilidad de la norma contenida en el Código Civil en relación con el matrimonio homosexual (sentencia Rol No. 1881). 
Son muchos los artículos especializados que los profesores chilenos han escrito para sistematizar y apreciar críticamente la jurisprudencia del Tribunal en materia de inaplicabilidad de la ley. Entre esas obras se cuentan las de los profesores Eduardo Aldunate Lizana -Jurisprudencia constitucional 20062008- y Francisco Zúñiga Urbina con "Acciones de inaplicabilidad e inconstitucionalidad. Doctrina y jurisprudencia del Tribunal Constitucional sobre temas procesales", así como las diversas ponencias presentadas en jornadas especializadas, incluso de alumnos universitarios, y en obras colectivas. Un ejemplo de estas está constituido por los dos libros que hasta la fecha, ha publicado la Asociación Chilena de Derecho Constitucional en homenaje a grandes maestros del Derecho Público chileno: "Temas Actuales de Derecho Constitucional", libro homenaje al profesor Mario Verdugo Marinkovic, 2009 y "Estudios sobre Justicia Constitucional", libro homenaje a la profesora Luz Bulnes Aldunate, 2011.

Algunos de esos mismos artículos también han tenido una difusión más amplia a través del Anuario de Derecho Constitucional Latinoamericano que publica la Fundación Konrad Adenauer y de la Revista Iberoamericana de Derecho Procesal Constitucional, editada por el Instituto Iberoamericano de Derecho Procesal Constitucional.

No puedo dejar de mencionar los aportes realizados por los ex Ministros del Tribunal Constitucional: por dos de sus ex Presidentes, José Luis Cea Egaña y Juan Colombo Campbell, quienes han sistematizado su experiencia en la serie Cuadernos del Tribunal Constitucional y en diversos artículos publicados en revistas especializadas. También cabe destacar la obra "Inaplicabilidad por inconstitucionalidad en la jurisprudencia del Tribunal Constitucional" que condensa la experiencia del ex Ministro Jorge Correa Sutil, así como el texto "Criterios de hermenéutica constitucional aplicados por el Tribunal Constitucional", del ex Ministro, Eugenio Valenzuela Somarriva, publicado en la serie Cuadernos del Tribunal Constitucional. En un sentido similar, el ex 
Ministro Mario Fernández Baeza ha dejado constancia de su opinión especialmente en relación con el debate suscitado en torno a la modificación experimentada por la ley orgánica del Tribunal Constitucional, en una reciente publicación de la Revista de Derecho Público de la Universidad de Chile.

La pregunta lógica que despierta toda esta actividad intelectual es ¿qué influencia tiene en el quehacer del Tribunal Constitucional?

Para dar respuesta a esa pregunta, recurriremos a algunos ejemplos que puedan ilustrar una conclusión.

Uno de los puntos interesantes develados por la doctrina ha hecho referencia a la naturaleza del control concreto de la actual acción de inaplicabilidad por inconstitucionalidad de la ley cuestionando algunos de los primeros fallos dictados por el Tribunal Constitucional en ejercicio de su nueva competencia. En el artículo del profesor José Manuel Díaz de Valdés Juliá, denominado "Inconstitucionalidad del artículo 116 del Código Tributario: primera sentencia constitucional derogatoria de una norma legal" (Revista Actualidad Jurídica $N^{\circ}$ 16, Universidad del Desarrollo, Santiago, julio de 2007), se planteó que las diversas sentencias que habían declarado la inaplicabilidad de la aludida norma del Código Tributario razonaban mucho más en el sentido de una inconstitucionalidad en abstracto que sobre la base del sentido concreto con que el Constituyente de 2005 dotó a este tipo de requerimiento.

Sin duda, debe reconocerse que ésta ha sido un punto sobre el cual el Tribunal ha meditado pudiendo distinguirse distintas posiciones entre sus miembros. Con todo, existe ya una nutrida jurisprudencia que atiende a la naturaleza de control concreto de dicha acción donde las circunstancias particulares del asunto sometido a su decisión son fundamentales a la hora de adoptarse la decisión. Por ejemplo, puede examinarse la sentencia recaída en el Rol № 707, de 25 de octubre de 2007, en que las circunstancias del caso concreto llevaron al Tribunal Constitucional a rechazar la acción de inaplicabilidad deducida respecto de algunos preceptos contenidos en el 
Decreto ley № 2695, de 1979, sobre regularización de la pequeña propiedad raíz (especialmente su considerando 13o).

Por lo demás, es esa forma de apreciar la naturaleza de la acción de inaplicabilidad por inconstitucionalidad la que permite entender por qué, tratándose de un mismo precepto legal impugnado, en algunos casos se acoge la acción, mientras que, en otros, se desestima. Pueden consultarse, en este sentido, las sentencias Roles №s 599, de 7 de junio de 2007 y 781 , de 27 de septiembre del mismo año.

En otras situaciones, la crítica de la doctrina se ha dirigido a aspectos puntuales de las sentencias dictadas por el Tribunal Constitucional.

Una de esas críticas apuntó a que el Tribunal había desaprovechado la oportunidad generada por la dictación de la primera sentencia de inconstitucionalidad de un auto acordado de los tribunales superiores de justicia -según la nueva competencia que le otorgó el artículo 93 № 2o de la Carta Fundamental- para precisar los requisitos exigibles a la acción respectiva. Dicho comentario se originó con ocasión de la sentencia dictada en el Rol № 783, de 31 de agosto de 2007. En posteriores sentencias referidas a la misma materia, el Tribunal Constitucional acogió esa crítica de la doctrina indicando con precisión, los requisitos que debían concurrir para que se ejerciese la acción respectiva, como las sentencias Roles №s 1812, 1816 y 1817 , todas del 18 de agosto de 2011, en particular su considerando $3^{\circ}$.

Otro ejemplo incide en el comentario realizado con ocasión de una sentencia que se pronunció sobre la inaplicabilidad del artículo 206 del Código Civil, referido a la posibilidad de deducir acción de reclamación de paternidad contra los herederos del padre o madre fallecido, en la que el Tribunal había 
desarrollado la tesis de que, en el conflicto de constitucionalidad sometido a su conocimiento, estaba en juego el "derecho a la identidad personal", entendido como una emanación de la dignidad humana y como un derecho que se encontraba implícito en nuestra Carta Fundamental (Rol № 1340). Desde la doctrina se criticó esta argumentación señalando, entre otros razonamientos, que el derecho a la identidad se traduce solamente en la inscripción del nombre respectivo en el Servicio de Registro Civil e Identificación (Rodríguez Grez, 2010). En sentencias posteriores, en las cuales varió la decisión del tribunal, producto de su nueva composición, el derecho a la identidad personal fue desarrollado en un voto de minoría, pero poniendo esta vez el acento en su carácter de derecho esencial que emana de la naturaleza humana, en el lenguaje utilizado por el inciso segundo del artículo $5^{\circ}$ de la Carta Fundamental. Véase, por ejemplo, la sentencia recaída en el Rol № 1656, de 1ํㅡㄹ

\section{A MODO DE CONCLUSIÓN}

Mucho pudiera decirse sobre el recurso de la doctrina por parte del Tribunal Constitucional chileno. Creo que una expresión que resume esa interacción es la de un "flujo permanente" donde el Tribunal se nutre de ella, aunque no necesariamente acoge sus críticas.

Se ha criticado, por algunos, el recurso a citas de jurisprudencia y de doctrina en la medida que ello lleva a fallos de una extensión considerable. Desde esas perspectivas, sería preferible un razonamiento más directo del propio Tribunal.

Pensamos, no obstante, que la particular naturaleza de la Constitución, que es un instrumento jurídico-político, con un fuerte contenido axiológico y con una gran cantidad de conceptos jurídicos indeterminados debiera llevar a mirar con buenos ojos el recurso a la doctrina y a la jurisprudencia de otros tribunales para ilustrar las decisiones de los jueces constitucionales. $\mathrm{Si}$, como 
sostiene Häberle, la Constitución es la expresión de la cultura de cada pueblo, dicho recurso exige actuar con prudencia cuando se trata de apoyarse en elementos que obedecen a realidades constitucionales diversas.

\section{REFERENCIAS BIBLIOGRÁFICAS}

- Zúñiga Urbina F. (2010). Acciones de inaplicabilidad e inconstitucionalidad. Doctrina y jurisprudencia del Tribunal Constitucional sobre temas procesales. Editorial Abeledo Perrot. Santiago.

- Cea Egaña, J. L. (2009) Una mirada al espíritu y la obra del Tribunal Constitucional. En: Asociación Chilena de Derecho Constitucional. Temas Actuales de Derecho Constitucional. Libro homenaje al profesor Mario Verdugo Marinkovic, Santiago, 2009.

- Díaz de Valdés Juliá, J. M. (2007). Inconstitucionalidad del artículo 116 del Código Tributario: primera sentencia constitucional derogatoria de una norma legal. Revista Actualidad Jurídica № 16, Universidad del Desarrollo.

- Asociación chilena de Derecho (2011). Estudios sobre Justicia Constitucional, libro homenaje a la profesora Luz Bulnes Aldunate. Editorial Jurídica de Chile. Santiago.

- Hans-Heinrich J.(1978) Tratado de derecho penal, parte General (1er volumen). Barcelona: Ed. Bosch.

- Jurisprudencia constitucional 2006-2008. Editorial Legal Publishing 2006-2008, Santiago, 2009.

- Peña Torres, M. (2006) Los desafíos para la justicia constitucional chilena a partir de la reforma de 2005. Suprema Corte de Justicia de la Nación de México. Colección Tribunales Constitucionales de Iberoamérica.

- Rodríguez Grez, P. (2010). Constitucionalización del derecho. Revista Actualidad Jurídica, № 22, Universidad del Desarrollo. 
- Pfeffer Urquiaga, E. y Bulnes Aldunate, L. (2009).Temas actuales de Derecho Constitucional, libro homenaje al profesor Mario Verdugo Marinkovic. Editorial Jurídica de Chile, Santiago.

\section{Documentos jurídicos y gubernamentales}

- Chile, Constitución Política, Santiago de Chile.

- Chile, (1985, enero), "Sentencia Rol N²1".

- Chile, (2007, abril), "Sentencia Rol № 707".

- Chile, (2007, diciembre), "Sentencia Rol N 790".

- Chile, (2008, marzo), "Sentencia Rol № 755".

- Chile, (2009, julio), "Sentencia Rol N 1.254".

- Chile, (2010, abril), "Sentencia Rol No 1273".

- Chile, (2011, agosto), "Sentencias Roles №s 1812, 1816 y 1817".

- Chile, (2011, septiembre), "Sentencia Rol No 1556".

- Chile, "Sentencia Rol № 1".

- Chile, "Sentencia Rol N 740".

- Chile, "Sentencia Rol No 1288".

- Chile, "Sentencia Rol № 1340".

- Chile, "Sentencia Rol № 1710".

- Chile, "Sentencia Rol № 1881". 